\title{
Dinâmica da regeneração natural em uma floresta baixa de restinga degradada ${ }^{1}$
}

\author{
Marcelo Augusto Meratti de Oliveira ${ }^{2,6}$, André Cruz de Oliveira ${ }^{2}$, Lucia Rossi ${ }^{3}$, \\ Eduardo Luis Martins Catharino ${ }^{4}$, Eduardo Pereira Cabral Gomes ${ }^{5}$ e Nelson Augusto dos Santos Junior ${ }^{2}$
}

Recebido: 30.04.2015; aceito: 5.10.2015

\begin{abstract}
Dynamics of the natural regeneration in a degraded low sandbank forest). This study aimed to characterize the composition of the seed rain and the seed bank in a degraded low sandbank forest to verify the inflow and establishment of the seed diaspores in the area under evaluation, its natural regeneration and contribution of the nearby remnants. At Ilha Comprida, in a degraded site, ten samples were taken monthly $\left(1 \mathrm{~m}^{2}\right.$ each $)$ for the seed rain and quarterly $\left(0.25 \mathrm{~m}^{2}\right.$ each $)$ for the seed bank, during the period of a year. In a the nearby remnant, arboreous individual with DBH $\geq 3 \mathrm{~cm}$ were sampled in the phytosociology study. During the specified period, 1627 diaspores were sampled in the seed rain and 2986 diaspores in the seed bank, and 356 individuals were sampled in the phytosociology study. The presence of Clusia criuva, Gaylussacia brasiliensis, Myrcia ilheoensis, Tapirira guianensis, and Tibouchina clavata in the seed rain and seed bank, considered nucleation species, with high biotic potential or little limitation of dispersion, can allow successional development in the area. The density and quality of species arriving and settling in the area have the potential to help it regenerate naturally.
\end{abstract}

Keywords: dynamic ecosystems, seed bank, seed rain

RESUMO - (Dinâmica da regeneração natural em uma floresta baixa de restinga degradada). Este estudo teve como objetivo caracterizar a composição da chuva e banco de sementes em uma floresta baixa de restinga degradada, a fim de verificar o aporte e estabelecimento dos diásporos na área e a contribuição dos remanescentes próximos para a regeneração natural. Num trecho degradado em Ilha Comprida, dez coletas mensais ( $1 \mathrm{~m}^{2}$ cada) para a chuva de sementes e trimestrais $\left(0,25 \mathrm{~m}^{2}\right.$ cada) para o banco de sementes foram realizadas durante um ano; e num remanescente vizinho amostraram-se indivíduos arbóreos com DAP $\geq 3 \mathrm{~cm}$ no estudo fitossociológico. Amostraram-se 1.627 diásporos na chuva de sementes, 2.986 no banco e 356 indivíduos no estudo fitossociológico. A presença de Clusia criuva, Gaylussacia brasiliensis, Myrcia ilheoensis, Tapirira guianensis e Tibouchina clavata na chuva e banco de sementes, consideradas espécies nucleadoras, de elevado potencial biótico ou pouca limitação de dispersão, podem possibilitar a sucessão na área. A densidade e qualidade de espécies que chegam por meio da chuva de sementes e que se estabelecem no banco de sementes indicam que a área pode se recuperar via regeneração natural.

Palavras-chave: dinâmica de ecossistemas banco de sementes, chuva de sementes

\section{Introdução}

A vegetação de restinga demonstra-se frágil e de difícil regeneração ou restauração em razão da composição de sua biota e de suas características edáficas que influenciam, dentre outros fatores, a ciclagem de nutrientes (Reis Duarte \& Casagrande
2006); no entanto, conhecer os atributos fisiológicos e ecológicos das espécies envolvidas nesse processo e as condições abióticas do local podem melhorar a compreensão de como ocorre a regeneração natural e subsidiar intervenções (Guariguata \& Ostertag 2002).

A dispersão nas comunidades de plantas tem sido identificada como um dos principais fatores

1. Parte da Dissertação de Mestrado do primeiro Autor

2. Instituto de Botânica, Núcleo de Pesquisa em Sementes, Av Miguel Stéfano 3687, Água Funda, 04301-012 São Paulo, SP, Brasil

3. Instituto de Botânica, Núcleo de Pesquisa Curadoria do Herbário de São Paulo, Av Miguel Stéfano 3687, Água Funda, 04301-012 São Paulo, SP, Brasil

4. Instituto de Botânica, Núcleo de Pesquisa - Orquidário do estado, Av Miguel Stéfano 3687, Água Funda, 04301-012 São Paulo, SP, Brasil

5. Instituto de Botânica, Núcleo de Pesquisa em Ecologia, Av Miguel Stéfano 3687, Água Funda, 04301-012 São Paulo, SP, Brasil

6. Autor para correspondência.mmeratti@gmail.com 
que influenciam a estrutura da comunidade vegetal (Götzenberger et al. 2012), pois por meio dela os diásporos são transportados por diferentes maneiras a certa distância da planta matriz, chegando a determinado local por meio da chuva de sementes que, por sua vez, abastece o banco de sementes e plântulas do solo da região (Silva et al. 2009). Estes processos são considerados o principal meio de regeneração das espécies tropicais (Garwood 1983, GromboneGuaratini \& Rodrigues 2002, Wang \& Smith 2002, Martini \& Santos 2007).

Os aspectos ecológicos de paisagem, como o tamanho e formato da área em questão, seu grau de isolamento, proximidade com corredores ecológicos e de fluxo genético, o tipo de matriz e presença de animais dispersores na área, interferem no fluxo de propágulos e, consequentemente, na estrutura da população (Parker 1997, Pivello et al. 2006).

A determinação do fluxo e estabelecimento destes diásporos no meio é essencial na compreensão do potencial regenerativo da vegetação (Nathan \& Muller-Landau 2000, Espíndola 2005), o que pode indicar qual tipo de comunidade irá compor o ambiente e em qual magnitude o restabelecimento dessas populações resultará na restauração dos processos que regem o funcionamento do sistema (Leite \& Rodrigues 2008, Campos et al. 2009).

O conhecimento dos diásporos presentes na chuva e no banco de sementes pode auxiliar na compreensão da dinâmica de regeneração natural de uma área degradada. Desta forma, o estudo tem por objetivo avaliar o potencial de regeneração natural de uma área degradada a partir da caracterização da composição da chuva e do banco de sementes. Também foi avaliada a composição florística e estrutural de um remanescente florestal do entorno, a fim de verificar a contribuição deste fragmento florestal para o processo de regeneração.

\section{Material e métodos}

Área de estudo - O estudo foi realizado na Área de Preservação Ambiental de Ilha Comprida, SP, em um trecho originalmente de floresta baixa de restinga, classificada de acordo com a Resolução CONAMA 07/96, de 27/07/1996 (CONAMA 1996). O clima é classificado como tropical úmido (Af), conforme Köppen (CEPAGRI 2013). O solo é caracterizado como arenoso, úmido e de cor branco-acinzentado (EMBRAPA 2006), não alagável.

Duas áreas experimentais foram utilizadas no estudo, tendo as mesmas como ponto de referência as coordenadas $24^{\circ} 53^{\prime} 57^{\prime \prime} \mathrm{S}$ e $47^{\circ} 47^{\prime} 24^{\prime \prime} \mathrm{WG}$, situado no limite entre as áreas. Na primeira área realizou-se a amostragem da chuva e banco de sementes. Essa área possui aproximadamente 1,5 ha e encontra-se em regeneração natural; sofreu corte raso da vegetação em 2001, foi abandonada e encontra-se em estágio inicial de sucessão, com vegetação rasteira de Cyperus sp., alguns indivíduos arbustivos de Gaylussacia brasiliensis e Tibouchina clavata e sem exemplares arbóreos. Na segunda área, vizinha à degradada e com aproximadamente o mesmo tamanho, foram realizados o levantamento florístico e o estudo fitossociológico. Essa área é caracterizada como floresta de restinga baixa, com vegetação predominantemente arbórea de pequeno porte e com sub-bosque composto por pteridófitas e bromélias.

Chuva de sementes - Foram utilizados dez coletores de madeira com $1 \mathrm{~m}^{2} \times 0,15 \mathrm{~m}$, confeccionados com fundo de tela agrícola de $50 \%$ e dispostos a $30 \mathrm{~cm}$ de altura do solo. A área degradada foi dividida em quadrados de $10 \mathrm{~m}^{2}$, dos quais 10 foram sorteados e neles colocado um coletor, evitando-se colocar os coletores abaixo dos arbustos da vegetação pré-existente. Sobre cada coletor foi colocada tela plástica de alambrado, com espaçamento entre os fios de $50 \mathrm{~mm}$, suficiente para permitir a passagem dos diásporos e impedir o seu consumo por parte da fauna local (Silva et al. 2009).

A coleta do material depositado ocorreu mensalmente, entre abril de 2012 e março de 2013. Contudo, para efeito de correlação com os dados obtidos no banco de sementes, os dados da chuva de sementes foram agrupados por trimestre. O material amostrado foi acondicionado em sacos de papel e levado para o laboratório do Núcleo de Pesquisa em Sementes (NPS) do Instituto de Botânica de São Paulo, onde foi triado manualmente com o auxílio de estereomicroscópio, separando-se os frutos e sementes de outros materiais eventualmente encontrados, como folhas, cascas de árvores, carapaças de insetos e esqueletos de pequenos vertebrados. As amostras de diásporos foram secas à sombra e em temperatura ambiente e, posteriormente, colocadas em sacos plásticos herméticos devidamente identificados.

Os frutos e sementes foram separados em morfotipos, sendo as sementes quantificadas por coletor. Para identificação, foram consultadas guias da literatura como Carrasco (2003), Couto \& Cordeiro (2005), Sampaio et al. (2005), a coleção de frutos/sementes (diasporoteca) do NPS, bem como 
o auxílio de pesquisadores dos Núcleos de Pesquisa em Sementes e Curadoria do Herbário de São Paulo. Quando não identificadas, as mesmas foram classificadas em morfoespécies.

Conforme as fórmulas apresentadas a seguir, a limitação de semente foi calculada a partir das fórmulas apresentadas em Muller- Landau et al. (2002); já a limitação de fonte, pelo método estocástico de Clark et al. (2001) e a limitação decorrente da dispersão de sementes, pelo proposto por Silva et al. (2009).

Limitação de sementes $=1-a / n$; sendo $a=$ número de coletores nos quais a semente foi coletada e $n=$ número total de coletores.

Limitação de fonte $=\exp (-s / n)$; sendo $s=$ número total de sementes coletadas e $n=$ número total de coletores. Limitação de dispersão $=1\{(\mathrm{a} / \mathrm{n}) / 1$ limitação de fonte\} Limitação de sementes/ limitação de dispersão.

Banco de sementes - A amostragem do banco de sementes foi realizada próxima aos coletores da chuva de sementes. As coletas dos materiais ocorreram ao final de cada estação do ano: março (verão), junho (outono), setembro (inverno) e dezembro (primavera) de 2012, de forma a quantificar o acúmulo sazonal de diásporos. Com o auxílio de gabarito de madeira de $0,5 \times 0,5 \mathrm{~m}$, foram coletadas 10 amostras de $0,25 \mathrm{~m}^{2}$ de solo em cada estação, totalizando 40 amostras e $10 \mathrm{~m}^{2}$ de solo coletados. Retirou-se a amostra de solo, com uma pá, a uma profundidade de $5 \mathrm{~cm}$ de solo e desprezou-se a serapilheira.

O material coletado foi embalado em sacos plásticos, identificado e posteriormente encaminhado ao laboratório da Unidade de Pesquisa e Tecnologia de Sementes (UPTS) do NPS para triagem, a qual ocorreu manualmente com o auxílio de uma peneira com 2,18 mm de abertura. Para não subestimar a densidade de sementes do banco, o restante do solo foi colocado para germinar em bandejas plásticas, visando à identificação dos diásporos por meio da emergência das plântulas (Price et al. 2010, Farnsworth et al. 2012). As bandejas foram acomodadas em casa de vegetação na UPTS, sob condições de luz natural e irrigada diariamente junto com uma bandeja controle, preenchida com areia esterilizada para amostrar as possíveis espécies invasoras da casa de vegetação.

A germinação das sementes foi avaliada quinzenalmente, ao longo de cinco meses, para cada estação amostrada. As plântulas que emergiam nas bandejas foram registradas, separadas por amostra e estação, identificadas até o menor taxon possível, fotografadas e removidas. Quando a identificação não foi possível, a muda era replantada em saco de polietileno contendo substrato comercial e mantida na casa de vegetação até ser possível sua identificação.

Os diásporos de indivíduos arbóreos encontrados na chuva e no banco de sementes, assim como as espécies amostradas no estudo fitossociológico, foram caracterizados de acordo com o grupo ecológico (pioneiras e não pioneiras) (São Paulo 2014). A categorização quanto ao hábito de vida (herbáceo, arbustivo, arbóreo e trepadeira), assim como quanto ao grupo ecológico dos demais estratos, foi baseado em Couto \& Cordeiro (2005). Todos os diásporos foram comparados em densidade e riqueza de espécies com a composição do remanescente próximo onde foi realizado o estudo fitossociológico. Também foram calculadas as densidades (D) anuais dos diásporos de cada espécie (Penhalber \& Mantovani 1997, Grombone-Guarantini \& Rodrigues 2002, Longhi et al. 2005).

A similaridade entre as estações e entre a composição dos indivíduos da chuva e do banco de sementes e aqueles amostrados no estudo fitossociológico foi feita pelo índice de similaridade de Jaccard (qualitativo, baseado na presença e ausência de espécies) e de Bray-Curtis (quantitativo, baseado no número de indivíduos por espécie). O dendrograma correspondente foi construído a partir do método da média aritmética entre pares não ponderados (UPGMA) por meio do programa PAST v. 2.08 (Hammer 2011).

Levantamento Fitossociológico - utilizou-se o método de parcelas contíguas, de acordo com MuellerDombois \& Ellenberg (1974). Uma parcela de $50 \times 50 \mathrm{~m}$, dividida em subparcelas de $10 \times 10 \mathrm{~m}$, foi delimitada com estacas de madeira e linha de nylon, conforme sugerido por Carrasco (2003).

Em cada parcela foram inventariados todos os indivíduos lenhosos vivos e mortos em pé, com diâmetro a 1,30 $\mathrm{m}$ de altura do solo igual ou superior a $3 \mathrm{~cm}$, dos quais foram coletados dados de perímetro com uso de fita métrica e de altura com o auxílio de uma vara telescópica. Aqueles incluídos neste critério e que também apresentaram ramificações inferiores a 1,30 m de altura do solo tiveram seus perímetros dos ramos anotados individualmente. Os indivíduos tiveram um ramo coletado, herborizado, identificado e depositado no NPS.

Foram calculados os parâmetros fitossociológicos (densidade, frequência, dominância, valor de importância e valor de cobertura) conforme Silva 
et al. (2009), sendo que as espécies foram ordenadas por ordem de família botânica para facilitar sua comparação com as espécies encontradas no banco e na chuva de sementes.

\section{Resultados e Discussão}

$\mathrm{Na}$ chuva de sementes foram coletados 1.627 diásporos ao longo de 12 meses, pertencentes a 18 famílias e 36 espécies, das quais 12 foram classificadas como morfoespécies. A maioria das famílias foi representada por apenas uma espécie, exceto Myrtaceae e Fabaceae com três espécies cada. Em todas as famílias foram amostrados indivíduos arbóreos, exceto para Bromeliaceae com duas espécies epífitas, Asteraceae com uma espécie arbórea e outra de forma indeterminada, e Smilacaceae com uma trepadeira (tabela 1).

Os diásporos presentes da chuva de sementes foram classificados como provenientes de espécies pioneiras $(54,8 \%)$, não pioneiras $(12,9 \%)$ e não classificadas $(32,4 \%)$. Com relação ao hábito, as formas de vida arbustiva (49,5\%) e arbórea (45,3\%), predominaram sobre as demais, herbácea $(1,5 \%)$, trepador $(0,5 \%)$ e epífitas $(0,1 \%)$. O percentual restante $(3,1 \%)$ não foi identificado.

A presença de diásporos de indivíduos pioneiros com as síndromes anemocórica e zoocórica é importante para a regeneração da área, pois após um distúrbio estes podem facilitar o processo de sucessão (Garwood 1989). Já a presença de um pequeno número de diásporos não pioneiros indica que a área encontra-se em estágio inicial de sucessão, porém apresenta potencial para dar continuidade ao processo de regeneração natural (López-Toledo \& MartínezRamos 2011).

A zoocoria $(86,9 \%)$ predominou sobre a anemocoria $(13,1 \%)$ e, dentre as espécies com dispersão zoocórica, 56,9\% foram arbustivas e 39,3\% arbóreas, o que corrobora com os dados de síndrome e porte encontrados em floresta estacional (Scherer 2004), em floresta ombrófila densa montana (Pivello et al. 2006) e em floresta alta de restinga (Silva et al. 2009); o percentual restante não foi classificado quanto ao hábito. O predomínio de diásporos com síndrome zoocórica na chuva de sementes é característico de áreas florestais conservadas (Morellato \& LeitãoFilho 1992, Piña-Rodrigues \& Aoki 2014); e também indica que a vegetação de entorno está em bom estado de conservação, uma vez que, em florestas perturbadas, o número de espécies anemocóricas tende a se aproximar da densidade de sementes zoocóricas (Penhalber 1995); além disso, esses fatores indicam que a área possui resiliência.

Gaylussacia brasiliensis e Ossaea retropila, que são espécies pioneiras e com síndrome de dispersão zoocórica (Oliveira et al. 2001, Carrasco 2003, Espíndola 2005), foram aquelas que predominaram na chuva de sementes, provavelmente em razão de seus padrões reprodutivos, pois ambas florescem e frutificam durante o ano inteiro ofertando alimento para a fauna local, fato também verificado por Rodrigues (2006) e Araújo et al. (2011).

A densidade média mensal obtida foi de 162,7 sementes $\mathrm{m}^{-2}$, valor inferior a 883,5 sementes $\mathrm{m}^{-2}$ encontrado na floresta alta de restinga de Ilha Comprida (Silva et al. 2009), 294,9 sementes $\mathrm{m}^{-2}$ na floresta baixa de restinga de Ilha do Cardoso (Faria 2008), 244,3 sementes $m^{-2}$ nas áreas abertas de restinga de Santa Catarina (Espíndola 2005), porém próximo a 127,5 sementes $\mathrm{m}^{-2}$ na floresta alta de restinga em regeneração inicial de Bertioga (Rodrigues 2006).

A baixa densidade de propágulos amostrados pode estar relacionada ao histórico de degradação que a área sofreu, uma vez que áreas degradadas apresentam menor probabilidade de receber sementes (Espíndola 2005), além do fato de uma floresta baixa de restinga apresentar menor riqueza de espécies e predomínio de alguns grupos de espécies em relação a florestas alta de restinga (Araujo\& Lacerda 1987, Sugiyama 1998).

A área apresentou indivíduos arbustivos com muitas ramificações, como Gaylussacia brasiliensis, que frutificou durante boa parte do ano, atraindo a fauna e servindo como poleiro. O mesmo foi observado para muitos indivíduos de espécies de pequeno porte, ofertando alimento para a avifauna. Indivíduos com este padrão tendem a assumir um importante papel para a chegada e estabelecimento dos diásporos em áreas degradadas (Reis et al. 2003). Apesar de não quantificado no presente trabalho, também foi verificada a presença de fezes com sementes em alguns coletores.

Clusia criuva, Myrcia ilheoensis e Ternstroemia brasiliensis, também presentes no estudofitossociológico, foram as espécies com os menores valores em relação à limitação de dispersão (respectivamente $0,3,0,2$ e 0 ). Silva et al. (2009) também registraram baixa limitação de dispersão das mesmas espécies em floresta alta de restinga.

Erythroxylum amplifolium foi a espécie mais abundante e com maior valor de importância na estrutura da área vizinha; no entanto, a espécie 


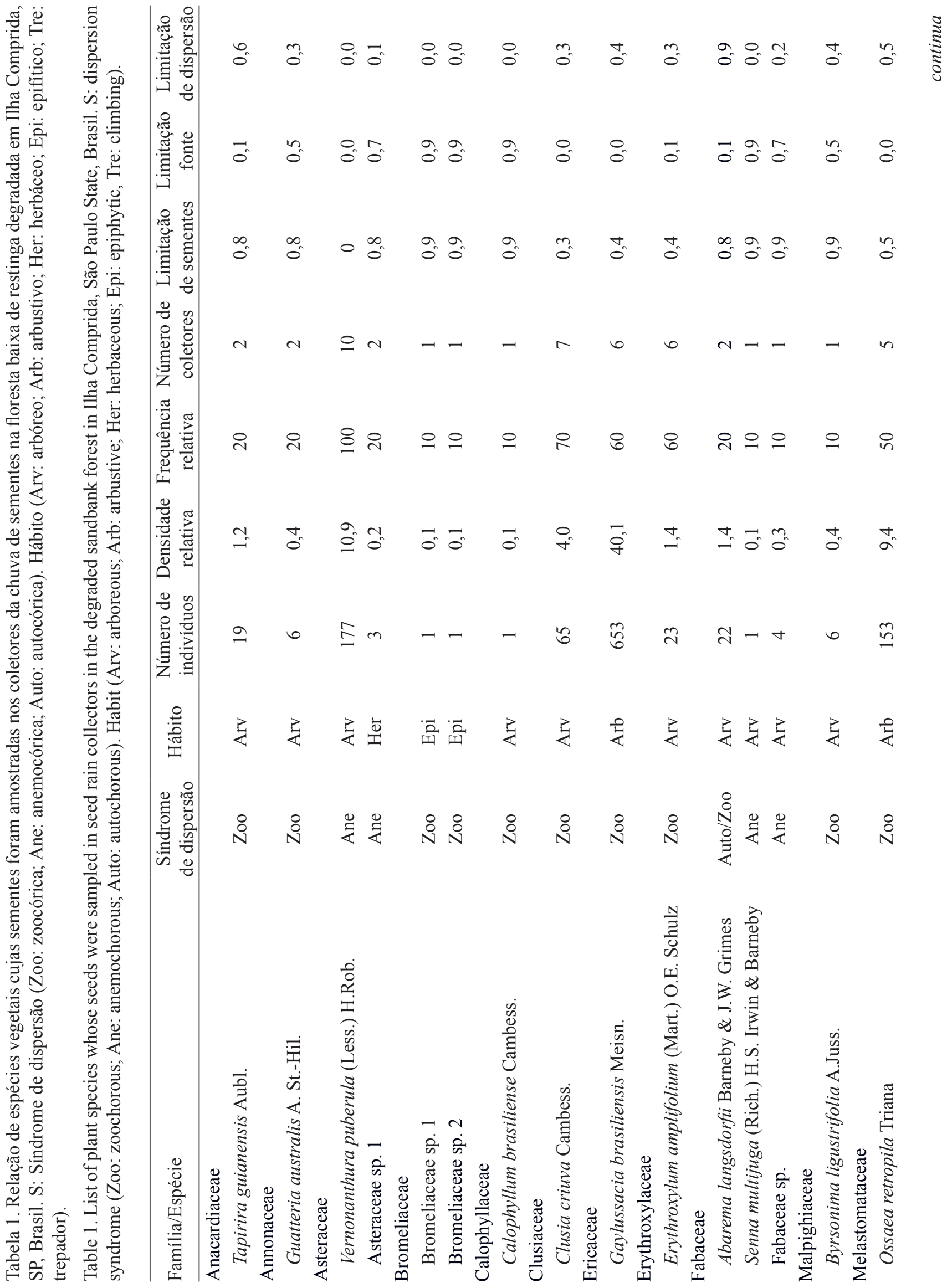




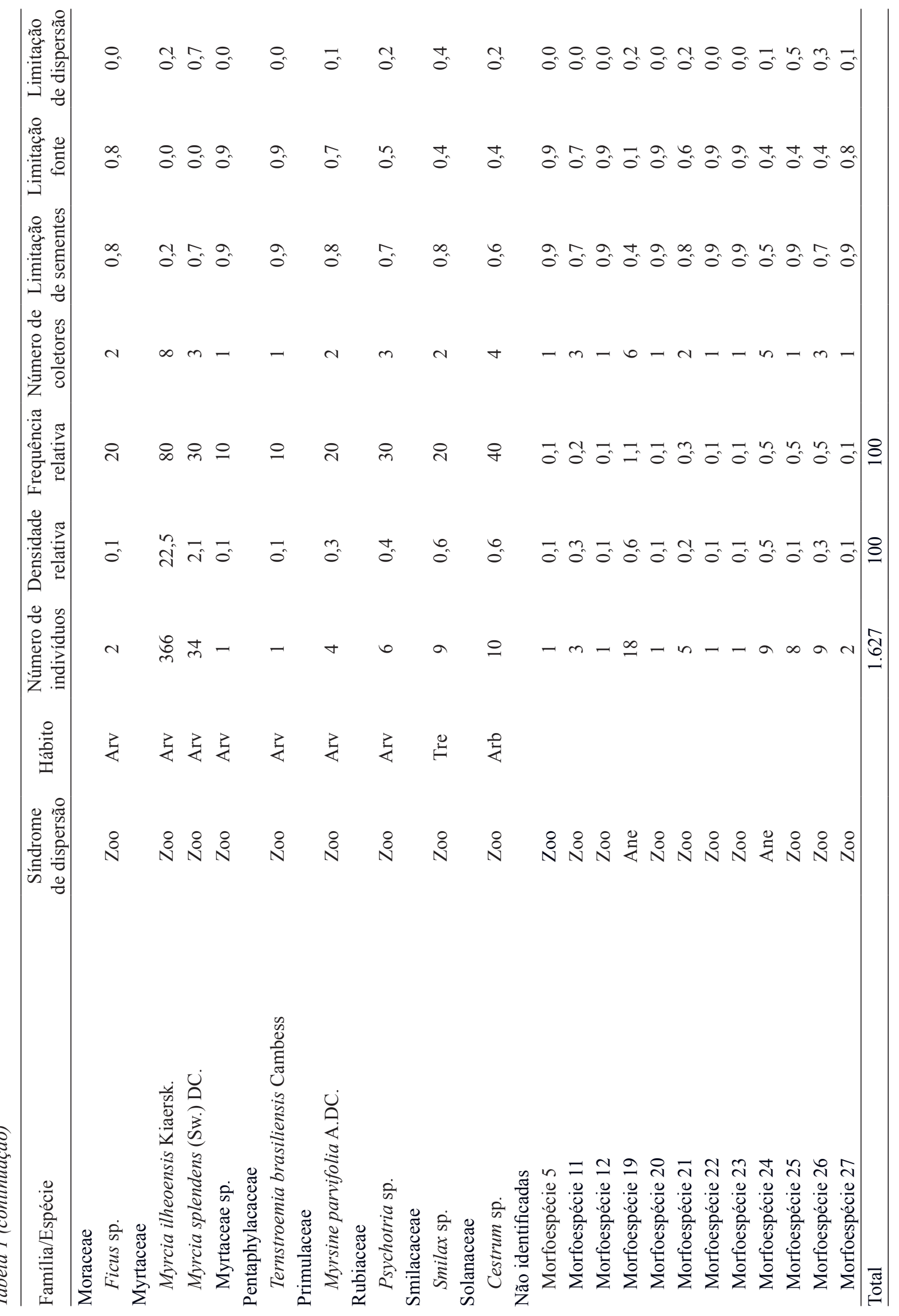


foi representada por valores reduzidos na chuva e banco de sementes, provavelmente em decorrência da limitação de sementes e da dispersão, 0,4 e 0,3, respectivamente, que pode estar relacionada com o seu curto período de frutificação (Marques \& Oliveira 2004). Psidium cattleianum ( $4^{\mathrm{a}}$ espécie em VI na área adjacente) não foi amostrado na chuva de sementes deste estudo, corroborando com Silva et al. (2009) que consideraram a espécie com limitação de sementes e dispersão.

As espécies amostradas na área degradada tiveram o maior número de diásporos depositados nos coletores durante janeiro, fevereiro e março, mesmo período encontrado por Penhalber \& Mantovani (1997) em mata secundária, Grombone-Guaratini \& Rodrigues (2002), em Floresta Estacional Semidecídua e Marques \& Oliveira (2004), em floresta de restinga. Todos esses autores salientaram um padrão fortemente sazonal na produção e dispersão de diásporos. Nas amostras deste estudo pode-se observar um pico de dispersão e germinação de espécies pioneiras e arbustivas no verão (figuras 1a e 1b) que, em geral, é a época mais favorável para a dispersão e estabelecimento das espécies (Morellato \& Leitão-Filho 1992).

Nos coletores da chuva de sementes, as espécies arbóreas mantiveram distribuição mais homogênea durante três estações, entretanto, no inverno houve aumento de diásporos arbóreos (figura 2a), o que pode ser explicado pela quantidade e limitação de dispersão de sementes de Vernonanthura puberula, espécie ausente no entorno, mas com propágulos depositados nos coletores. Esta espécie apresenta dispersão anemocórica densa e uniforme (Wunderle Jr. 1997), associada à estação seca devido à caducifolia e a maior intensidade dos ventos (Campos 2009, Silva 2009).

No banco de sementes foram amostrados 2.986 diásporos, portanto a densidade de sementes para a área foi de 299 sementes $\mathrm{m}^{-2}$, valor muito inferior ao encontrado por Vinha (2008), em floresta ombrófila densa $\left(1.261\right.$ sementes $\left.\mathrm{m}^{-2}\right)$, porém superior ao encontrado por Rodrigues (2006), em floresta de restinga em São Vicente, SP (269 sementes $\mathrm{m}^{-2}$ ).

A indução do banco de sementes não deve ser a única técnica a ser empregada na restauração de áreas (Pivelo et al. 2006). Com base nos resultados obtidos neste estudo, acredita-se que esta afirmação também é válida para o banco de sementes do local amostrado; apesar da densidade de sementes por metro quadrado estar dentro de padrões já descritos em outros estudos, o estoque de sementes apresenta baixa densidade de espécies pioneiras de hábito arbóreo ou arbustivo.
Os diásporos coletados foram distribuídos em 21 famílias e um grupo de não identificados. Dentre os identificados, quatro estão no nível de família, seis de gênero, 17 com binômio completo e 18 classificados como morfoespécies. Melastomataceae e Poaceae foram as famílias mais representativas (1.071 e 760 diásporos amostrados, respectivamente), ambas com três espécies cada. Tibouchina clavata e Poaceae sp. 1 foram aquelas com maior frequência e densidade no banco sementes (tabela 2).

Espécies herbáceas normalmente são encontradas em banco de sementes de áreas degradadas (Putz \& Appanah 1987, Garwood 1989). Neste estudo, elas representaram $70,9 \%$ do total amostrado. Predomínio de herbáceas também foi relatado em estudos no banco de sementes de uma Floresta Estacional Semidecídua Montana degradadas para o plantio de Eucalyptus (Costalonga et al. 2006), em Floresta de Restinga sob talhão de Pinus (Vieira 2004), e em uma Floresta de Restinga degradada por mineração (Rodrigues 2006).

Dentre as espécies arbustivas e arbóreas, Tapirira guianensis, G. brasiliensis, P. cattleianum e Pera glabrata foram aquelas com maior percentual de diásporos no banco de sementes. Todas elas são consideradas de importância para a conservação e restauração de áreas degradadas por produzirem e dispersarem grande quantidade de sementes que são fonte de alimento para elevado número de espécies (Lenza \& Oliveira 2005, Barbieri \& Heiden 2009, Lorenzi 2009, Araújo et al. 2011, Freitas et al. 2011).

A presença de Tibouchina clavata em praticamente todas as amostras do banco de sementes e de C. criuva na chuva de sementes e no entorno é um indicativo de que essas espécies são importantes para a recuperação de áreas degradadas, visto que são nucleadoras e com elevado potencial biótico (Scarano 2002, Santos Jr. 2005, Rodrigues 2006). Portanto, podem favorecer a formação de microhábitats, permitindo a germinação e o crescimento de outras espécies na área e, consequentemente, acelerar o avanço sucessional na área degradada.

O elevado número de espécies pioneiras no banco de sementes era esperado, pois estas são comuns no banco de sementes (Harper 1977, Simpson et al. 1989). Espécies secundárias adotam como estratégia a formação do banco de plântulas (Valk \& Pederson 1989), o que muitas vezes pode inviabilizar o seu estabelecimento em áreas degradadas.

A predominância de diásporos herbáceos e sua distribuição homogênea no banco de sementes deste estudo (figura $2 \mathrm{~b}$ ) pode ser explicada pelo histórico de degradação da área (Marques 2002). 
Atrelado a isto, fatores como ausência ou presença de dormência e ainda condições edáficas, de temperatura e pluviosidade podem influenciar a densidade e dominância de espécies no banco de sementes (Miao \& Zou 2009, Silva-Weber et al. 2012).

A maior precipitação durante o verão (SAISP 2013) pode ter sido suficiente para que espécies arbóreas como T. guianensis, P. catleyanum e Ficus sp. apresentassem grandes quantidades de diásporos amostrados neste período. Provavelmente, partes dos diásporos amostrados são de períodos anteriores ao da chuva de sementes amostrada neste estudo, já que essas espécies mantém estoques de sementes viáveis no solo por longos períodos (Garwood 1989, Simpson et al. 1989).

No estudo fitossociológico foram amostrados 356 indivíduos, (excluindo-se cinco indivíduos mortos) distribuídos em 12 famílias, 15 gêneros e 23 espécies (tabela 3). A densidade total obtida foi de 1.444 ind ha-1 e a área basal de $15,14 \mathrm{~m}^{2} \mathrm{ha}^{-1}$, sendo que os indivíduos mortos em pé somaram 20 ind ha $^{-1}$ com área basal de $0,04 \mathrm{~m}^{2} \mathrm{ha}^{-1}$.
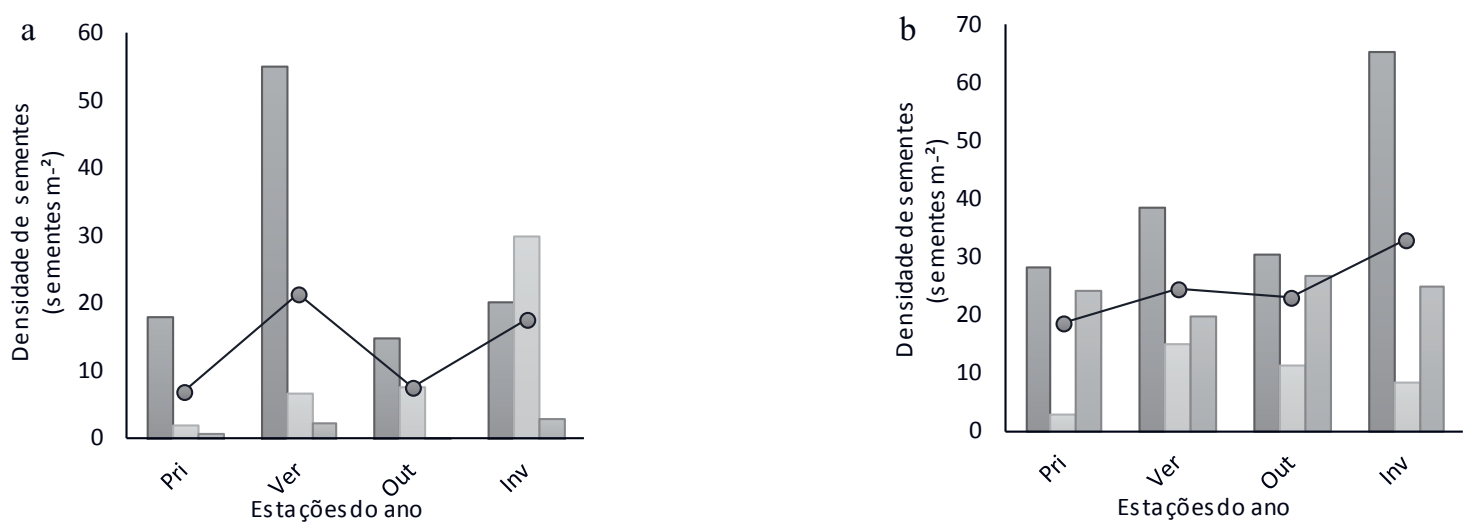

Figura 1. Densidade de sementes por metro quadrado de amostras na chuva (a) e no banco de sementes (b) ao longo de 2012, apresentadas de acordo com sua classe sucessional. P: pioneira; NP: não pioneira e NC: não classificada.

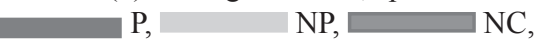
$\longrightarrow$ Média.

Figure 1. Density of seeds per square meter sampled in the seed rain (a) and the seed bank (b) throughout 2012, presented in accordance with their successional. P: pioneer; NP: not pioneer; and NC: not rated. $\mathrm{P}, \quad \mathrm{NP}$, $\mathrm{NP}, \square$, Average.
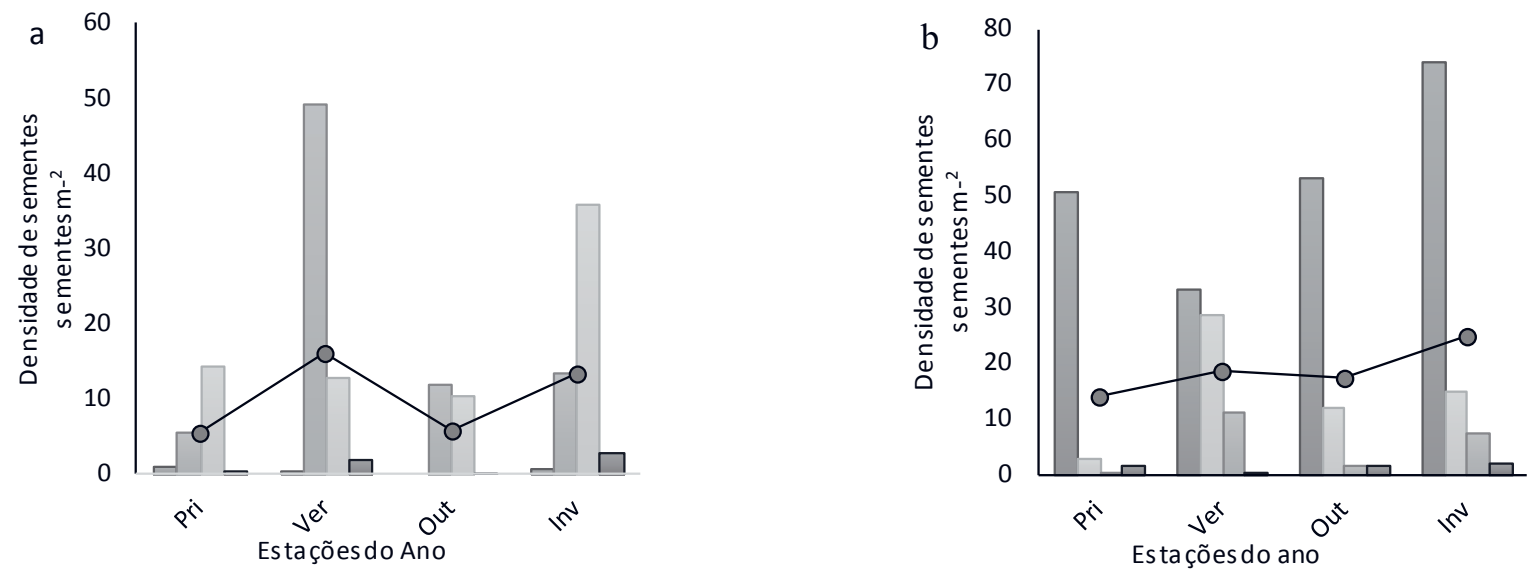

Figura 2. Densidade de sementes por metro quadrado: amostras na chuva (a) e no banco de sementes (b) ao longo de 2012, apresentadas de acordo com seu hábito. HER: herbácea; ARB: arbustivo; ARV: arbóreo e NI: não classificado. $\square$ HER, $\square$ ARB, ARV, NI, —— Média.

Figure 2. Density of seeds per square meter sampled in the seed rain (a) and the seed bank (b) throughout 2012, presented in accordance with their habit. HER: herbaceous; ARB: arbustive; ARV: arboreous and NI: not rated.

HER, ARB, ARV, $\mathrm{NI}, \longrightarrow$ - Average. 
Tabela 2. Relação de espécies vegetais cujas sementes foram encontradas no banco de sementes amostrado na floresta baixa de restinga degradada em Ilha Comprida, SP, Brasil. S: Síndrome de dispersão (Zoo: zoocórica; Ane: anemocórica; Auto: autocórica). Hábito (Arv: arbóreo; Arb: arbustivo; Her: herbáceo; Epi: epifítico; Tre: trepador).

Table 2. List of plant species whose seeds were found in the seed bank collected in a degraded coastal sandbank forest in Ilha Comprida, São Paulo State, Brazil. S: dispersion syndrome (Zoo: zoochorous; Ane: anemochous; Auto: autochorous). Habit (Arv: arboreous; Arb: arbustive; Her: herbaceous; Epi: epiphytic; Tre: climbing).

\begin{tabular}{|c|c|c|c|c|c|c|}
\hline Família/ Espécie & Hábito & Síndrome & $\begin{array}{l}\text { Número de } \\
\text { indivíduos }\end{array}$ & $\begin{array}{l}\text { Número de } \\
\text { coletores }\end{array}$ & $\begin{array}{l}\text { Densidade } \\
\text { relativa }\end{array}$ & $\begin{array}{l}\text { Frequência } \\
\text { relativa }\end{array}$ \\
\hline \multicolumn{7}{|l|}{ Anacardiaceae } \\
\hline Tapirira guianensis Aubl. & Arv & Zoo & 200 & 5 & 6,7 & 1,9 \\
\hline \multicolumn{7}{|l|}{ Asteraceae } \\
\hline Senecio ceratophylloides Griseb. & Her & Ane & 38 & 8 & 1,3 & 3,1 \\
\hline \multicolumn{7}{|l|}{ Cyperaceae } \\
\hline Scleria latifolia $\mathrm{Sw}$. & Her & Zoo & 115 & 16 & 3,9 & 6,2 \\
\hline \multicolumn{7}{|l|}{ Ericaceae } \\
\hline Gaylussacia brasiliensis Meisn. & Arb & Zoo & 199 & 12 & 6,7 & 4,6 \\
\hline \multicolumn{7}{|l|}{ Erythroxylaceae } \\
\hline $\begin{array}{l}\text { Erythroxylum amplifolium (Mart.) } \\
\text { O.E. Schulz }\end{array}$ & Arv & Zoo & 3 & 2 & 0,1 & 0,8 \\
\hline \multicolumn{7}{|l|}{ Euphorbiaceae } \\
\hline Euphorbia heterophylla L. & Her & Aut & 4 & 1 & 0,1 & 0,4 \\
\hline \multicolumn{7}{|l|}{ Fabaceae } \\
\hline Abarema sp. & Arb & Ane & 1 & 1 & 0,0 & 0,4 \\
\hline Dimorphandra sp. & Arv & Ane & 1 & 1 & 0,0 & 0,4 \\
\hline \multicolumn{7}{|l|}{ Iridaceae } \\
\hline Neomarica candida Sprague & Her & Ane & 10 & 8 & 0,3 & 3,1 \\
\hline \multicolumn{7}{|l|}{ Lamiaceae } \\
\hline Lamiaceae sp. & Her & Ane & 2 & 1 & 0,1 & 0,4 \\
\hline \multicolumn{7}{|l|}{ Malpighiaceae } \\
\hline Byrsonima ligustrifolia A. Juss. & Arb & Zoo & 6 & 3 & 0,2 & 1,2 \\
\hline \multicolumn{7}{|l|}{ Melastomataceae } \\
\hline Ossaea retropila Triana & Arb & Zoo & 13 & 1 & 0,4 & 0,4 \\
\hline Miconia cinnamomifolia Triana & Arb & Ane & 10 & 2 & 0,3 & 0,8 \\
\hline Tibouchina clavata (Pers.) Wurdack & Her & Ane & 1048 & 34 & 35,1 & 13,1 \\
\hline \multicolumn{7}{|l|}{ Moraceae } \\
\hline Ficus sp. & Arv & Zoo & 55 & 17 & 1,8 & 6,5 \\
\hline \multicolumn{7}{|l|}{ Myrtaceae } \\
\hline Myrcia ilheoensis Kiaersk. & Arv & Zoo & 32 & 13 & 1,1 & 5,0 \\
\hline Psidium cattleianum Sabine & Arv & Zoo & 112 & 4 & 3,8 & 1,5 \\
\hline \multicolumn{7}{|l|}{ Pentaphylacaceae } \\
\hline Ternstroemia brasiliensis Cambess & Arv & Zoo & 18 & 11 & 0,6 & 4,2 \\
\hline \multicolumn{7}{|l|}{ Peraceae } \\
\hline Pera glabrata Poepp. ex Baill. & Arv & Zoo & 133 & 16 & 4,5 & 6,2 \\
\hline \multicolumn{7}{|l|}{ Poaceae } \\
\hline Poaceae sp. 1 & Her & Ane & 732 & 36 & 24,5 & 13,9 \\
\hline Poaceae sp. 2 & Her & Ane & 1 & 1 & 0,0 & 0,4 \\
\hline Poaceae sp. 3 & Her & Ane & 27 & 5 & 0,9 & 1,9 \\
\hline
\end{tabular}


Tabela 2 (continuação)

\begin{tabular}{|c|c|c|c|c|c|c|}
\hline Família/ Espécie & Hábito & Síndrome & $\begin{array}{l}\text { Número de } \\
\text { indivíduos }\end{array}$ & $\begin{array}{c}\text { Número de } \\
\text { coletores }\end{array}$ & $\begin{array}{c}\text { Densidade } \\
\text { relativa }\end{array}$ & $\begin{array}{c}\text { Frequência } \\
\text { relativa }\end{array}$ \\
\hline \multicolumn{7}{|l|}{ Primulaceae } \\
\hline Myrsine sp. & Arv & Zoo & 13 & 10 & 0,4 & 3,9 \\
\hline \multicolumn{7}{|l|}{ Rubiaceae } \\
\hline Psychotria carthagenensis Jacq. & Arv & Zoo & 2 & 2 & 0,1 & 0,8 \\
\hline \multicolumn{7}{|l|}{ Smilacaceae } \\
\hline Smilax sp. & Tre & Zoo & 8 & 3 & 0,3 & 1,2 \\
\hline \multicolumn{7}{|l|}{ Solanaceae } \\
\hline Solanum americanum Mill. & Her & Zoo & 52 & 7 & 1,7 & 2,7 \\
\hline \multicolumn{7}{|l|}{ Xyridaceae } \\
\hline Abolboda sp. & Her & Ane & 76 & 6 & 2,6 & 2,3 \\
\hline \multicolumn{7}{|l|}{ Não identificadas } \\
\hline Morfoespécie 1 & Arb & Zoo & 7 & 2 & 0,2 & 0,8 \\
\hline Morfoespécie 2 & - & Zoo & 1 & 1 & 0,0 & 0,4 \\
\hline Morfoespécie 3 & - & Zoo & 5 & 4 & 0,2 & 1,5 \\
\hline Morfoespécie 4 & - & Zoo & 2 & 2 & 0,1 & 0,8 \\
\hline Morfoespécie 5 & - & Zoo & 6 & 2 & 0,2 & 0,8 \\
\hline Morfoespécie 6 & - & Zoo & 3 & 1 & 0,1 & 0,4 \\
\hline Morfoespécie 7 & - & Zoo & 11 & 6 & 0,4 & 2,3 \\
\hline Morfoespécie 8 & - & Zoo & 17 & 4 & 0,6 & 1,5 \\
\hline Morfoespécie 9 & - & Zoo & 3 & 1 & 0,1 & 0,4 \\
\hline Morfoespécie 10 & - & Zoo & 1 & 1 & 0,0 & 0,4 \\
\hline Morfoespécie 11 & - & Zoo & 5 & 1 & 0,2 & 0,4 \\
\hline Morfoespécie 12 & - & Zoo & 1 & 1 & 0,0 & 0,4 \\
\hline Morfoespécie 13 & - & Zoo & 3 & 2 & 0,1 & 0,8 \\
\hline Morfoespécie 14 & - & Zoo & 1 & 1 & 0,0 & 0,4 \\
\hline Morfoespécie 15 & - & Zoo & 1 & 1 & 0,0 & 0,4 \\
\hline Morfoespécie 16 & - & Zoo & 1 & 1 & 0,0 & 0,4 \\
\hline Morfoespécie 17 & - & Zoo & 1 & 1 & 0,0 & 0,4 \\
\hline Morfoespécie 18 & Her & Ane & 6 & 1 & 0,0 & 0,4 \\
\hline Soma & & & 2.986 & & 100 & 100 \\
\hline Média & & & $\begin{array}{c}66,4 \\
(+189,2) \\
\text { sementes } \mathrm{m}^{-2}\end{array}$ & & $2,2(+6,3)$ & $22(+3)$ \\
\hline
\end{tabular}

As famílias de maior riqueza foram Myrtaceae (nove espécies) e Primulaceae (com duas espécies). Já as famílias com maior número de indivíduos foram Myrtaceae (com 116 indivíduos, 32,1\% do total amostrado), Erythroxylaceae $(92,25,5 \%)$ e Celastraceae $(35,9,8 \%)$ que, juntas, corresponderam a $68,2 \%$ dos indivíduos amostrados, enquanto as outras 9 somaram 31,7\% (111 indivíduos). Estes dados corroboram os estudos realizados por Sugiyama (2003), Assis et al. (2004), Micheletti Neto (2007), que também encontraram a predominância destas famílias em vegetação de restinga.

Entre as espécies, destacaram-se E. amplifolium, Maytenus gonoclada, M. splendens, Laplacea fructicosa, P. cattleianum e M. Ilheoensis que, somadas, representaram $64 \%$ dos indivíduos amostrados e ocuparam as primeiras posições em valor de importância. Essas espécies são comuns em florestas de restinga, tendo sido registradas em Ilha Comprida (Carrasco 2003) e em Bertioga (Martins et al. 2008). 
Tabela 3. Descritores quantitativos das espécies amostradas no componente arbóreo da floresta baixa de restinga, adjacente à área degradada na Vila de Pedrinhas, Ilha Comprida, SP, Brasil. CS: classe sucessional; Np: Não pioneira; P: Pioneira; Ni: número de indivíduos; No: número de parcelas em que a espécie ocorreu; DoR: dominância relativa (\%); DR: densidade relativa (\%); FR: frequência relativa (\%); IVI: índice do valor de importância; IVC: índice do valor de cobertura; AM: altura média; PC: presente na chuva de sementes e PB: presente no banco de sementes.

Table 3. Quantitative descriptors of the species sampled in the arboreous component of the coastal sandbank forest, adjacent to the degraded area in Vila de Pedrinhas, Ilha Comprida, São Paulo State, Brazil. CS: successional class; Np: Not pioneer; P: Pioneer; Ni: number of individuals; No: number of plots where the species occurred; DoR: relative dominance (\%); DR: relative density (\%); FR: relative frequency (\%); IVI: index value of importance; IVC: coverage index value; AM: average height; PC: present in the seed rain; and PB: present in the seed bank.

\begin{tabular}{|c|c|c|c|c|c|c|c|c|c|c|c|}
\hline Família/Espécie & $\mathrm{CS}$ & $\mathrm{Ni}$ & No & DoR & DR & FR & IVI & IVC & $\mathrm{AM}$ & $\mathrm{PC}$ & PB \\
\hline \multicolumn{12}{|l|}{ Celastraceae } \\
\hline Maytenus gonoclada Reissek & $\mathrm{Np}$ & 35 & 17 & 9,6 & 9,8 & 9,2 & 28,7 & 19,4 & 4,6 & $\mathrm{x}$ & \\
\hline \multicolumn{12}{|l|}{ Clusiaceae } \\
\hline Clusia criuva Cambess. & $\mathrm{P}$ & 18 & 13 & 3,1 & 5,1 & 7,1 & 15,2 & 8,1 & 4,2 & $\mathrm{x}$ & \\
\hline \multicolumn{12}{|l|}{ Erythroxylaceae } \\
\hline Erythroxylum amplifolium (Mart.) O.E. Schulz & $\mathrm{Np}$ & 92 & 24 & 29,2 & 25,8 & 13 & 68,1 & 55 & 4,4 & $\mathrm{x}$ & $\mathrm{x}$ \\
\hline \multicolumn{12}{|l|}{ Fabaceae } \\
\hline Andira fraxinifolia Benth. & $\mathrm{Np}$ & 4 & 4 & 0,6 & 1,1 & 2,2 & 3,9 & 1,7 & 3,8 & & \\
\hline \multicolumn{12}{|l|}{ Lauraceae } \\
\hline Ocotea pulchella (Nees \& Mart.) Mez & $\mathrm{Np}$ & 13 & 9 & 2,6 & 3,7 & 4,9 & 11,1 & 6,2 & 3,8 & & \\
\hline \multicolumn{12}{|l|}{ Melastomataceae } \\
\hline Miconia cinnamomifolia (DC.) Naudin & $\mathrm{Np}$ & 13 & 8 & 1,4 & 3,7 & 4,4 & 9,4 & 5,1 & 4,4 & & $\mathrm{x}$ \\
\hline \multicolumn{12}{|l|}{ Myrtaceae } \\
\hline Eugenia sulcata Spring. ex Mart. & $\mathrm{Np}$ & 14 & 9 & 3,7 & 3,9 & 4,9 & 12,5 & 7,6 & 4,0 & & \\
\hline Eugenia sp. & - & 6 & 5 & 0,6 & 1,7 & 2,7 & 5,0 & 2,3 & 4,4 & & \\
\hline Myrcia splendens (Sw.) DC. & $\mathrm{Np}$ & 29 & 14 & 7,4 & 8,2 & 7,6 & 23,2 & 15,6 & 4,3 & & \\
\hline Myrcia ilheoensis Kiaersk. & $\mathrm{Np}$ & 23 & 12 & 7,2 & 6,5 & 6,5 & 20,2 & 13,6 & 4,9 & $\mathrm{x}$ & $\mathrm{x}$ \\
\hline Myrcia multiflora (Lam.) DC. & $\mathrm{Np}$ & 15 & 12 & 5,7 & 4,2 & 6,5 & 16,4 & 9,9 & 4,5 & & \\
\hline Myrcia sp. 1 & - & 3 & 1 & 0,5 & 0,8 & 0,5 & 1,9 & 1,4 & 4,6 & & \\
\hline Psidium cattleianum Sabine & $\mathrm{Np}$ & 22 & 16 & 6,5 & 6,2 & 8,7 & 21,4 & 12,7 & 4,6 & & \\
\hline Myrtaceae sp. 2 & - & 1 & 1 & 0,9 & 0,3 & 0,5 & 1,7 & 1,2 & 4,6 & & \\
\hline Myrtaceae sp. 3 & - & 3 & 3 & 2,8 & 0,8 & 1,6 & 5,2 & 3,6 & 5,4 & & \\
\hline \multicolumn{12}{|l|}{ Nyctaginaceae } \\
\hline Guapira opposita (Vell.) Reitz & $\mathrm{Np}$ & 6 & 2 & 0,9 & 1,7 & 1,1 & 3,7 & 2,6 & 4,0 & & \\
\hline \multicolumn{12}{|l|}{ Pentaphylacaceae } \\
\hline Ternstroemia brasiliensis Cambess & $\mathrm{Np}$ & 13 & 9 & 6,3 & 3,7 & 4,9 & 14,9 & 10,0 & 4,7 & $\mathrm{x}$ & $\mathrm{x}$ \\
\hline \multicolumn{12}{|l|}{ Peraceae } \\
\hline Pera glabrata (Schott) Poepp. ex Baill. & $\mathrm{P}$ & 10 & 5 & 1,2 & 2,8 & 2,7 & 6,7 & 4,0 & 4,3 & & $\mathrm{x}$ \\
\hline \multicolumn{12}{|l|}{ Primulaceae } \\
\hline Myrsine coriacea (Sw.) R.Br. ex Roem. \& Schult. & $\mathrm{P}$ & 1 & 1 & 0,1 & 0,3 & 0,5 & 0,9 & 0,4 & 4,5 & & \\
\hline Myrsine umbellata Mart. & $\mathrm{Np}$ & 3 & 2 & 0,6 & 0,8 & 1,1 & 2,5 & 1,5 & 4,6 & $\mathrm{x}$ & $\mathrm{x}$ \\
\hline \multicolumn{12}{|l|}{ Indeterminadas } \\
\hline Indet sp. 1 & - & 2 & 2 & 0,1 & 0,6 & 1,1 & 1,7 & 0,7 & 4,3 & & \\
\hline Indet sp. 2 & - & 1 & 1 & 2,9 & 0,3 & 0,5 & 3,7 & 3,2 & 8,0 & & \\
\hline \multicolumn{12}{|l|}{ Theaceae } \\
\hline Laplacea fructicosa (Schrad.) Kobuski & $\mathrm{Np}$ & 29 & 14 & 6,4 & 8,2 & 7,6 & 22,1 & 14,5 & 3,9 & & \\
\hline Total & & 356 & & & & & & & & & \\
\hline
\end{tabular}


Associado ao registro de C. criuva e T. brasiliensis, estes resultados indicam que a área de estudo se encontra em estádio avançado de regeneração, uma vez que essas espécies são consideradas de estágio intermediário e final da sucessão (CONAMA 1996, Couto \& Cordeiro 2005).

Dentre as espécies com valores de importância mais expressivos destacaram-se as não pioneiras (14 espécies, ou seja, mais da metade das espécies), evidenciando um provável estágio primário ou avançado de desenvolvimento para a comunidade adjacente. Esta é uma condição importante para a regeneração da área degradada, já que remanescentes adjacentes contribuem dispersando diásporos na chuva e banco de sementes (Penhalber \& Mantovani 1997, Espíndola 2005). Por meio dos agrupamentos evidenciados nas análises de similaridade de Jaccard (figura 3a) e Bray-Curtis (figura 3b), constatou-se que as amostras do banco de sementes foram as que apresentaram os maiores valores de similaridade. Já as amostras da chuva de sementes apresentaram similaridade menor, outro indício de que a chuva de sementes é mais influenciada pela sazonalidade. Como no estudo fitossociológico foram amostrados apenas indivíduos arbóreos, excluindo-se os outros hábitos, os grupos encontrados neste indicado ficaram isolados dos demais grupos do banco e chuva de sementes.

Geralmente, além das espécies arbóreas, estão presentes na composição da chuva de sementes as espécies arbustivas, herbáceas e em alguns casos trepadeiras (Campos et al. 2009), o que pode justificar a dissimilaridade florística entre os indivíduos arbóreos presentes nas parcelas da fitossociologia e os indivíduos coletadas na chuva de sementes.

M. ilheoensis, G. brasiliensis e, em menor número, E. amplifolium e T. brasiliensis foram registradas na chuva de sementes, no banco de sementes e na fitossociologia. No entanto, a presença dessas espécies em comum não fui suficiente para aumentar a similaridade florística entre os grupos, devido ao registro de espécies exclusivas em cada componente: Poaceae sp. 1 e T. clavata foram registradas em elevada densidade apenas no banco de sementes, $V$. puberula e $O$. retropila na chuva de sementes e $L$. fructicosa e M. gonoclada somente na fitossociologia.

Pela análise quantitativa, o grupo formado do banco de sementes foi o mais homogêneo em riqueza e densidade de espécies, distanciando-o dos demais grupos em decorrência da alta densidade de espécies herbáceas, não contemplada na amostragem fitossociológica e em baixa densidade na chuva de sementes.

O banco de sementes apresentou maior similaridade com a chuva de sementes na análise qualitativa (índice de Jaccard, figura 3a) comparada à quantitativa (índice de Bray-Curtis, figura 3b). Este resultado está relacionado à composição da matriz de análise; além de diferenças na composição de espécies de chuva e banco de sementes, essas espécies foram registradas em diferentes proporções de propágulos na matriz quantitativa, resultando em menor similaridade.

A semelhança entre as espécies amostradas na chuva e no banco de sementes pode indicar pouca limitação para o recrutamento e favorecimento para aqueles indivíduos que, de acordo com a chegada, ocupam os espaços disponibilizados aleatoriamente (Miyazaki 2009). Em geral, as herbáceas presentes na chuva e no banco de sementes apresentam potencial para colonizar áreas num primeiro momento após a perturbação, revegetando-a (Araujo et al. 2004). Entretanto, na sequência, pode ocorrer competição ou inibição do desenvolvimento da vegetação de porte arbóreo ou arbustivo, o que pode indicar que a restauração necessite da intervenção antrópica para acontecer.

As espécies características de etapas mais avançadas do processo de regeneração, como T. guianensis, O. retropila, G. brasiliensis e C. criuva (Gandolfi 2000, Carrasco 2003, Couto \& Cordeiro 2005), igualmente constatadas nas amostragens da chuva e do banco de sementes deste trabalho, indicam que apesar do distúrbio oriundo do corte raso da vegetação em 2001, estas potencialmente poderão tomar parte no processo de recomposição natural da vegetação, na medida em que condições para o seu estabelecimento e desenvolvimento forem criadas.

\section{Conclusões}

Diásporos de espécies pioneiras predominaram na chuva de sementes em três das quatro estações do ano, assim como propágulos de espécies arbustivas em duas das quatro estações do ano. Durante todo o período, a síndrome de dispersão zoocórica foi a mais frequente.

O predomínio de diásporos de espécies pioneiras também foi observado no banco de sementes, mas prevaleceram os propágulos de espécies de porte herbáceo e de síndrome de dispersão anemocórica.

A riqueza de espécies e a quantidade de diásporos amostrados nos compartimentos da chuva e do banco de sementes da área degradada foram relativamente altos, indícios de que a área pode se regenerar naturalmente. 

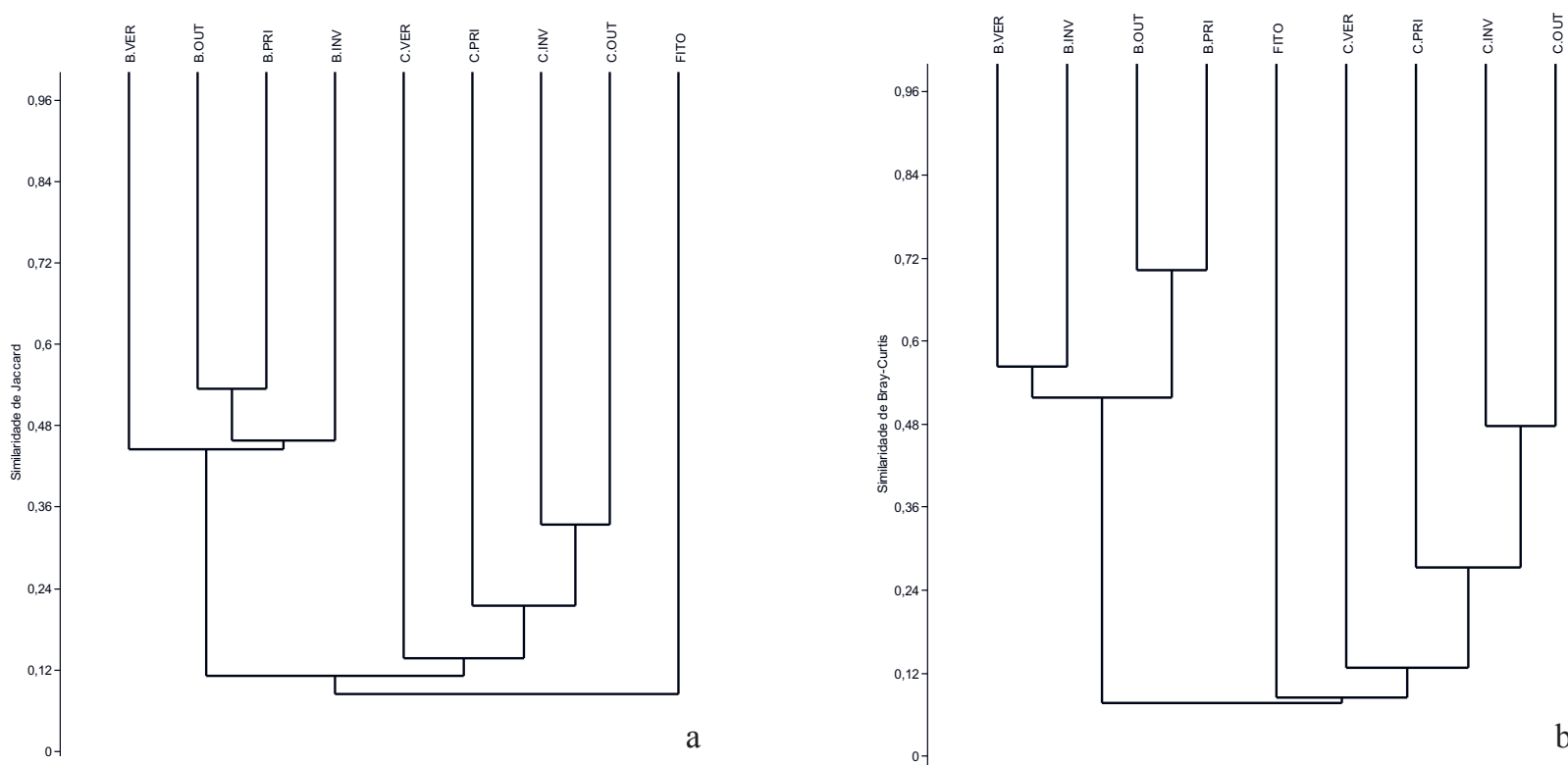

Figura 3. Dendrograma de similaridade florística obtido pelo método de ligação de média de grupo (UPGMA), com base no índice de similaridade de Jaccard (a) e Bray-Curtis (b), ambos com coeficiente cofenético = 0,975, das amostras do banco de sementes do verão (B.VER), inverno (B.INV), outono (B.OUT) e primavera (B.PRI), chuva de sementes do verão (C.VER), primavera (C.PRI), inverno (C.INV) e outono (C.OUT) e do Estudo fitossociológico (FITO) na floresta baixa de restinga degradada por corte raso de vegetação na Vila de Pedrinhas, Ilha Comprida, SP, Brasil.

Figure 3. Dendrogram of floristic similarity obtained by the unweighted pair group method with arithmetic mean (UPGMA) based on the Jaccard (a) and Bray-Curtis similarity (b), both with a cophenetic coefficient of 0.975 , of samples of the seed bank during the summer (B.VER), winter (B.INV), autumn (B.OUT), and spring (B.PRI), of the seed rain during the summer (C.VER), spring (C.PRI), winter (C.INV), and autumn (C.OUT) and the phytosociology study (PHYTO) in the degraded coastal sandbank forest by clear-cutting of vegetation in Vila de Pedrinhas, Ilha Comprida, São Paulo State, Brazil.

A floresta de restinga adjacente contribuiu de forma positiva para ambos os processos, o que ressalta a importância destes remanescentes como fonte de propágulos para a regeneração natural da área degradada. Dentre as espécies mais abundantes e amostradas no estudo fitossociológico do trecho de floresta primária, E. amplifolium, M. splendens e $M$. ilheoensis foram registradas na chuva de sementes e E. amplifolium, P. cattleianum e M. ilheoensis no banco de sementes.

A avaliação conjunta dos indicadores mostrou-se importante para inferir a resiliência da área e a contribuição de cada componente para o avanço sucessional, se baseado apenas na regeneração natural, a qual na floresta baixa de restinga tende a ocorrer de forma mais lenta e gradativa em relação a outras formações da Mata Atlântica.

\section{Agradecimentos}

Ao CNPq, pela bolsa de estudos concedida; à toda equipe de apoio do Núcleo de Pesquisa de Sementes do Instituto de Botânica e do Núcleo de Pesquisa Curadoria do Herbário SP, pelo suporte com os materiais; ao Paulo Henrique de Oliveira Santos, pelo auxílio com a versão do Abstract e revisão desde o início deste estudo; à Cristiane Pires Andrioli (SAISP), por disponibilizar os dados climatológicos da área.

\section{Literatura citada}

Assis, A.M., Pereira, O.J. \& Thomaz L.D. 2004. Fitossociologia de uma floresta de restinga no Parque Estadual Paulo César Vinha, Setiba, município de Guarapari (ES). Revista Brasileira de Botânica 27: 349-361.

Araujo, D.S.D. \& Lacerda, L.D. 1987. A Natureza das Restingas. Ciência Hoje 6: 42-48.

Araujo, M.M., Longui, S.J., Barros, P.L.C. \& Brena D.A. 2004. Caracterização da Chuva de sementes, banco de sementes do solo e banco de plântulas em Floresta Estacional decidual ripária Cachoeira do Sul, RS, Brasil. Scientia Florestalis 66: 128-141.

Araújo, F.P., Farias, Y.E.F. \& Oliveira, P.E. 2011. Biologia floral e visitantes de Gaylussacia brasiliensis (Spr.) Meissner (Ericaceae): uma espécie com anteras poricidas polinizada por beija-flores. Acta Botanica Brasilica 25: 387-394. 
Barbieri, R.L. \& Heiden, G. 2009. Árvores de São Mateus do Sul e região. Embrapa Informação Tecnológica, Brasília.

Campos, E.P., Vieira, M.F., Francisco, A., Martins, S.V., Carmo, F.M.S., Moura, V.M. \& Ribeiro A.S.S. 2009. Chuva de sementes em Floresta Estacional Semidecidual em Viçosa, MG, Brasil. Acta Botanica Brasilica 23: 451-458.

Carrasco, P.G. 2003. Produção de mudas de espécies florestais de restinga, com base em estudos florísticos e fitossociológicos, visando a recuperação de áreas degradadas, em Ilha Comprida - SP. Tese de Doutorado, Universidade Estadual Paulista Julio de Mesquita Filho, Rio Claro.

Centro de Pesquisas Meteorológicas e Climáticas Aplicadas a Agricultura (CEPAGRI). 2013. Clima dos municípios paulistas. Centro de Pesquisas Meteorológicas e Climáticas Aplicadas a Agricultura, Campinas. Disponível em http://www.cpa.unicamp.br/ outras-informacoes/clima_muni_235.html (acesso em 26-X-2013).

Clark, C.J., Poulsen, J.R. \& Parker, V.T. 2001. The role of arboreal seed dispersal groups on the seed rain of a lowland tropical forest. Biotropica 33: 606-620.

Conselho Nacional do Meio Ambiente (CONAMA). 1996. Resolução CONAMA 007/96. CONAMA, Brasília, DF, de 23-VII-1996. Conselho Nacional do Meio Ambiente, Brasília, Disponível em http://www.fflorestal.sp.gov.br/ media/uploads/bertioga/Resolucao\%20CONAMA $\% 20$ n\%20 07-96.htm (acesso em 10-IX-2010).

Costalonga, S.R., Reis, G.G., Reis, M.G.F., Silva, A.F., Lima e Borges, E.E. \& Guimarães F.P. 2006. Florística do banco de sementes do solo em áreas contíguas de pastagem degradada, plantio de eucalipto e floresta em Paula Cândido, MG. Floresta 36: 239-250.

Couto, O.S. \& Cordeiro, R.M.S. 2005. Manual de reconhecimento de espécies vegetais da restinga do estado de São Paulo. Secretaria do Meio Ambiente, Departamento do Estado de Proteção de Recursos Naturais - DEPRN - São Paulo, São Paulo.

EMBRAPA-Empresa Brasileira de Pesquisa Agropecuária. 2006. Sistema brasileiro de classificação de solos. 2ed. EMBRAPA Solos, Rio de Janeiro.

Espíndola, M.B. 2005. O papel da chuva de sementes na restauração da restinga do Parque Florestal do Rio Vermelho, Florianópolis-SC. Dissertação de Mestrado, Universidade Federal de Santa Catarina, Florianópolis.

Faria, M.B.B.C. 2008. Diversidade e regeneração natural de árvores em Florestas de Restinga na Ilha do Cardoso, Cananéia, SP, Brasil. Dissertação de Mestrado, Instituto de Biociências, São Paulo.

Farnsworth, E.J., Plotkin, A.A.B. \& Ellison, A.M. 2012. The relative contributions of seed bank, seed rain, and understory vegetation dynamics to the reorganization of Tsuga canadensis forests after loss due to logging or simulated attack by Adelges tsugae. Canadian Journal of Forest Research 42: 2090-2105.
Freitas, J.R., Figueiredo, R.A., Nadai, I.C. \& Hardman L. 2011. Aspectos da ecologia reprodutiva de Pera glabrata (Schott) Poepp. ex Baill. (Euphorbiaceae) em uma área de cerrado no estado de São Paulo. Árvore 35: 1227-1234.

Gandolfi, S. 2000. História natural de uma floresta estacional semidecidual no Município de Campinas (São Paulo, Brasil). Tese de Doutorado, Universidade Estadual de Campinas, São Paulo.

Garwood, N.C. 1983. Seed germination in a seasonal tropical forest in Panama: a community study. Ecological Monographs 53: 159-181.

Götzenberger, L., de Bello, F., Bråthen, K.A., Davison, J., Dubuis, A., Guisan, A., Lepš, J., Lindborg, R., Moora, M., Pärtel, M., Pellissier, L., Pottier, J., Vittoz, P., Zobel, K. \& Zobel M. 2012. Ecological assembly rules in plant communities - approaches, patterns and prospects. Biological Reviews 87: 111-127.

Grombone-Guarantini, M.T. \& Rodrigues, R.R. 2002. Seed bank and seed rain in a seasonal semi-deciduous forest in South-Eastern Brazil. Journal of Tropical Ecology 18: 759-774.

Guariguata, M. R. \& Ostertag, R. 2002. Sucesión secundaria. In: M.R. Guariguata, G.H. Kattan (eds.). Ecologia y conservation de bosques Neotropicales. LUR, San Jose, pp. 561-623.

Hammer, Ø. 2011. Paleontological Statistics: Version 2.16: manual do usuário. Natural History Museum University, Oslo.

Harper, J.L. 1977. Population biology of plants. Academic Press, Londres.

Leite, E.C. \& Rodrigues, R.R. 2008. Fitossociologia e caracterização sucessional de um fragmento de Floresta Estacional no sudeste do Brasil. Árvore 32: 583-595.

Lenza, E. \& Oliveira, P.E. 2005. Biologia reprodutiva de Tapirira guianensis Aubl. (Anacardiaceae), uma espécie dióica em mata de galeria do triângulo mineiro, Brasil. Revista Brasileira de Botânica 1: 179-190.

Longhi, S.J., Brun, E.J., Oliveira, D.M., Fialho, L.E.B., Wojciechowski, J.C. \& Varrarro, S. 2005. Banco de Sementes do solo em três fases sucessionais de uma Floresta Estacional Decidual em Santa Tereza, RS. Ciência Florestal 15: 359-370.

López-Toledo, L. \& Martínez-Ramos, M. 2011. The soil seed bank in abandoned tropical pastures: source of regeneration or invasion? Revista Mexicana de Biodiversidad 82: 663-678.

Lorenzi, H. 2009. Árvores brasileiras: manual de identificação e cultivo de plantas arbóreas nativas do Brasil. Instituto Plantarum, Nova Odessa.

Marques, M.M.C. 2002. Dinâmica da dispersão de sementes e regeneração de plantas da planície litorânea da Ilha do Mel, PR. Tese de Doutorado, Instituto de Biociências, São Paulo. 
Marques, M.C.M. \& Oliveira, E.A.M. 2004. Fenologia de espécies do dossel e do sub-bosque de duas florestas de restinga na Ilha do Mel, Sul do Brasil. Revista Brasileira de Botânica 2: 713-723.

Martini, A.M.Z. \& Santos, F.A.M. 2007. Effects of distinct types of disturbance on seed rain in the Atlantic forest of NE Brazil. Plant Ecology 190: 81-95.

Martins, S.E., Rossi, L., Salles, P. \& Sampaio, P. 2008. Caracterização florística de comunidades vegetais de restinga em Bertioga, SP, Brasil. Acta Botanica Brasilica 22: 249-274.

Miao, S. \& Zou, C.B. 2009. Seasonal variation in seed bank composition and its interaction with nutrient enrichment in the Everglades Wetlands. Aquatic Botany 90: 157-164.

Micheletti Neto, J.C.M.T. 2007. Relações florísticas, estruturais e ecológicas entre as florestas do topo da serra do mar e as florestas de restinga no estado de São Paulo. Dissertação de Mestrado, Universidade de São Paulo, São Paulo.

Miyazaki, S.L. 2009. Análise de estrutura, chuva de sementes e regeneração natural de populações de plantas em floresta de restinga alta, São Vicente-SP. Tese de Doutorado, Instituto de Botânica de São Paulo, São Paulo.

Morellato, L.P.C. \& Leitão-Filho, H.F. 1992. Padrões de frutificação e dispersão na Serra do Japi. In: L.P.C, Morellato (ed.). História Natural da Serra do Japi: ecologia e preservação de uma área florestal no Sudeste do Brasil. UNICAMP/FAPESP, Campinas, pp. 112-140.

Mueller-Dombois, D. \& Ellenberg, H. 1974. Aims and Methods of Vegetation ecology. Willey and Sons, New York.

Muller-Landau, H.C., Wright, J.P., Calderón, O., Hubbell, S.P. \& Foster, R.B. 2002. Assessing recruitment limitation: concepts, methods and casestudies from a tropical forest. In: D.J. Levey, W. R., Silva \& M. Galetti. (eds.). Seed dispersal and frugivory: ecology, evolution, and conservation. CABI Publishing, Wallingford, pp. 35-53.

Nathan, R. \& Muller-Landau, H.C. 2000. Spatial patterns of seed dispersal, their determinants and consequences for recruitment. Trends Ecology Evolution 15: 278-285.

Oliveira, R.J., Mantovani, W. \& Fiuza de Melo, M.M.R. 2001. Estrutura do componente arbustivo-arbóreo da Floresta Atlântica de encosta, Peruíbe, SP. Acta Botanica Brasilica 15: 391-412.

Parker, V.T. 1997. The scale of successional model and restoration objectives. Restoration Ecology, 5: 301-307.

Penhalber, E.F. \& Mantovani, W. 1997. Floração e chuva de sementes em Mata Secundária em São Paulo, SP. Revista Brasileira de Botânica 20: 205-220.

Piña-Rodrigues, F.C.M. \& Aoki, J. 2014. Chuva de sementes como indicadora do estádio de conservação de fragmentos florestais em Sorocaba - SP. Ciência Florestal 14: 911-923.
Pivello, V.R., Petenon, D., Jesus, F.M., Meirelles, S.T., Vidal, M.M., Alonso, R.A.S., Franco, G.A.D.C. \& Metzger, J.P. 2006. Chuva de sementes em fragmentos de Floresta Atlântica (São Paulo, SP, Brasil), sob diferentes situações de conectividade, estrutura florestal e proximidade da borda. Acta Botanica Brasilica 20: 845-859.

Price, J.N., Wright, B.R., Gross, C.L. \& Whalley, W.R.D.B. 2010. Comparison of seedling emergence and seed extraction techniques for estimating the composition of soil seed banks. Methods in Ecology and Evolution 1: 151-157.

Putz, F.E. \& Appanah, S. 1987. Buried seeds, newly dispersed seeds, and dynamics of a lowland forest in Malaysia. Biotropica 19: 326-333.

Reis, A., Bechara, F.C., Espíndola, M.B., Vieira, N.K. \& Souza, L.L. 2003. Restoration of damaged land areas: Using nucleation to improve sucessional processes. The Brazilian Journal of Nature Conservation 1: 85-92.

Reis-Duarte, R.M. \& Casagrande, J.C. 2006. A interação solo-planta na recuperação de áreas degradadas. In: L.M. Barbosa (coord.). Manual para recuperação de áreas degradadas do Estado de São Paulo: Matas Ciliares do Interior Paulista. Instituto de Botânica. pp. 52-69.

Rodrigues, M.A. 2006. Avaliação da chuva e banco de sementes em áreas de restinga, morfologia e potencial biótico de espécies ocorrentes nestes locais. Dissertação de Mestrado, Universidade Estadual Paulista Julio de Mesquita Filho, Rio Claro.

Sampaio, D, Souza, V.C., Oliveira, A.A., Rodrigues, R.R. \& Souza, J.P. 2005. Árvores da restinga: guia ilustrado para identificação das espécies da Ilha do Cardoso. Neotropica, São Paulo.

Santos Junior, N.A. 2005. Dinâmica da colonização natural em encostas degradadas da serra do mar, ecofisiologia e produção de mudas das espécies, como subsídio à recuperação florestal. Tese de Doutorado, Universidade Estadual Paulista Julio de Mesquita Filho, Rio Claro.

Secretaria do Meio Ambiente do Estado de São Paulo (SMA). 2014. Resolução SMA 32/14. Diário Oficial do Estado de São Paulo, Poder Executivo, São Paulo, 5-IV-2014, Seção I, pp. 36-37. Disponível em http:// www.ambiente.sp.gov.br/legislacao/files/2014/04/ Resolu\%C3\%A7\%C3\%A3o-SMA-032-2014-a.pdf (acesso em 2-III-2015).

Scarano, F.R. 2002. Structure, function and floristic relationships of plant communities in stressful habitats marginal to the Brazilian Atlantic rain forest. Annals of Botany 90: 517-524.

Scherer, C. 2004. Banco e chuva de sementes em uma floresta estacional no Sul do Brasil. Dissertação de Mestrado, Universidade Federal do Rio Grande do Sul, Porto Alegre. 
Silva, C.R., Barbosa, J.M., Carrasco, P.G., Castanheira, S.A., Pereira, M.A. \& Santos Junior, N.A. 2009. Chuva de sementes em uma floresta alta de restinga em Ilha Comprida (SP). Cerne 15: 355-365.

Silva-Weber, A.J.C., Nogueira, A.C., Carpanezzi, A.A., Galvão, F. \& Weber, S.H. 2012. Composição Florística e distribuição sazonal do banco de sementes em Floresta Ombrófila Mista Aluvial, Araucária, PR. Pesquisa Florestal Brasileira 32: 77-91.

Simpson, R. L., Leck, M. A. \& Parker, V. T. 1989. Seed banks: general concepts and methodological issues. In: M.A. Leck, V.T. Parker \& R.L. Simpson (eds.). Ecology of soil seed banks. Academic, London, pp. 3-8.

Sistema de Alerta a Inundações do Estado de São Paulo (SAISP). 2013. Radar Metereológico de Ponte Nova (Sistema de Alerta a Inundações do Estado de São Paulo, São Paulo. Disponível em http://www.saisp.br/estaticos/ sitenovo/home.xmlt (acesso em 26-XI-2013).

Sugiyama, M. 1998. Estudo de florestas de restinga na Ilha do Cardoso, Cananéia, São Paulo, Brasil. Boletim do Instituto de Botânica 11: 119-159.
Sugiyama, M. 2003. Estudos florísticos e fitossociológicos em comunidades vegetais de restinga da Ilha do Cardoso, Cananéia, SP. Tese de Doutorado, Universidade Federal de São Carlos, São Paulo.

Valk, A. G. van der \& Pederson, R. L. 1989. Seed bank and managenent and restoration of natural vegetation. In: M.A. Leck, V.T. Parker \& R.L. Simpson (eds.). Ecology of soil seed banks. Academic, San Diego, pp. 329-346.

Vieira, N.K. 2004. O papel do banco de sementes na restauração de restinga sob talhão de Pinus elliottii Engelm. Dissertação de Mestrado, Universidade Federal de Santa Catarina, Florianópolis.

Vinha, D. 2008. Banco de sementes em áreas com diferentes graus de perturbação no Parque Estadual das Fontes do Ipiranga, em São Paulo, SP. Dissertação de Mestrado, Instituto de Botânica de São Paulo, São Paulo.

Wang, B.C. \& Smith, T.B. 2002. Closing the seed dispersal loop. Review. Trends Ecology Evolution 17: 379-385.

Wunderle, J.M. 1997. The role of animal seed dispersal in accelerating natives forest regeneration on degraded tropical lands. Forest Ecology and Management 99: 223-235. 